\title{
Tıp Tarihi ile İgili Çalışmaların Web of Science Veri Tabanı Üzerinden Bibliyometrik
}

Analizi* $^{*}$

\author{
Bibliometric Analysis of Studies on the History of Medicine by Web of Science Database \\ Özgür Kuşi, Arif Hüdai Köken ${ }^{\mathrm{ii}}$
}

iPhD, Sağlık Bilimleri Üniversitesi, Gülhane Eğitim ve Araştırma Hastanesi Göz Kornea Birimi, https://orcid.org/0000-0002-0046-4572

iiDr. Öğr. Üyesi, Kırşehir Ahi Evran Üniversitesi, Tıp Fakültesi, Tıp Tarihi ve Etik Anabilim Dalı, https://orcid.org/0000-0003-2188-4741

öz

Amaç: Bu çalışmayla tıp tarihi alanına yönelik yapılan ve Web of Science veri tabanında yer alan yayınların bibliyometrik analizini yapmak, Türkiye'nin bu alana katkı düzeyini belirlemek ve araştırmacılara rehberlik edici nitelikte alana özgü en güncel literatür bilgisini sunmak amaçlanmıştır.

Yöntem: Web of Science (WOS) veri tabanında yer alan tüm indekslerde "tıp tarihi" alanında yapılan çalışmalar taranmıştır. Tarama sonucunda 1975-2020 yılları arasını kapsayan toplam 5904 çalışmaya ulaşılıış̧ır. Bu çalışmalar, bibliyometrik analizleri yapılarak tablo ya da şekil olarak sunulmuştur. Buna ilaveten Türkiye adresli çalışmalar ve yayınlar da analiz edilmiş, en fazla katkı sunan üniversiteler ve yazarlar ile en fazla atıf alan yayınlar tespit edilerek birer tabloda gösterilmiştir.

Bulgular: Analizler sonucunda tıp tarihine yönelik en fazla çalışmanın son beş yıllık dilim içerisinde ( $n=1364 ; \% 23,10)$ yapıldığı, İngilizce yayınların ilk sırada ( $n=4101 ; \% 69,46)$ bulunduğu, en aktif derginin Revista Medica de Chile ( $n=184 ; \% 3,11$ ) olduğu, en fazla çalışmanın Amerika Birleşik Devletleri'nden ( $n=1499 ; \% 25,39)$ çıktığı, Türkiye'nin ise 15 . sırada $(n=90 ; \% 1,52)$ yer aldığı görülmüştür. Türkiye adresli yayınlarda en fazla çalışmanın tarih ve cerrahi alanında yapıldığı, en çok yayın yapan kurumunun ise Ankara Üniversitesi olduğu belirlenmiştir.

Sonuç: Literatürde tıp tarihi ile ilgili çalışmalara özgü bütüncül ve kapsamlı olarak yapılmış bir bibliyometrik analize rastlanmamıştır. Dolayısıyla bu çalışmanın tıp tarihi literatürüne katkı sağlayacağı, bu alanda çalışma yapmayı planlayan araştırmacılara yol gösterici ve bilgilendirici bir nitelik taşıyacağı düşünülmektedir.

Anahtar kelimeler: Tıp Tarihi, Bibliyometrik Analiz, Web of Science

ABSTRACT

Objective: The aim of the study is to analyze the studies in the field of history of medicine that in the Web of Science database, to determine the level of Turkey's contribution to this area and to present the latest literature information specific to the field to guide researchers.

Methods: The studies about "history of medicine" were scanned in all indexes in the Web of Science (WOS) database. As a result of the scanning, a total of 5904 studies covering the years between 1975 and 2020 were reached. These studies were presented as tables or figures by making bibliometric analysis. In addition, the studies and publications from Turkey have been analyzed. The universities and authors that the most contributed and the most cited publications were identified and shown in a table.

Results: As a result of the analysis, it is seen that the most studies on the history of medicine were conducted within the last five years $(n=1364 ; 23.10 \%)$. The publications in English $(n=4101 ; 69.46 \%)$ take the first place. It is seen that the most active journal is Revista Medica de Chile ( $n=184 ; 3.11 \%)$. The most of the studies were from the United States of America $(n=1499 ; 25.39 \%)$. Turkey $(n=90 ; 1.52 \%)$ has been seen to rank in the 15th place. The most of the studies from Turkey are about history and surgery. It is seen that the institution with the most studies is Ankara University.

Conclusion: A holistic and comprehensive bibliometric analysis specific to studies on history of medicine has not been found in the literature. Therefore, it is thought that this study will contribute to the history of medicine literature and will have a guiding and informative quality for researchers who will study in this field.

KeyWords: History of Medicine, Bibliometric Analysis, Web of Science

${ }^{*}$ Lokman Hekim Dergisi, 2021; 11 (2): 364-374

DOI: 10.31020/mutftd.878803

e-ISSN: 1309-8004, ISSN 1309-761X

Geliş Tarihi - Received: 11 Şubat 2021; Kabul Tarihi - Accepted: 27 Nisan 2021

iletişim - Correspondence Author: Özgür Kuş <kus.ozgur@gmail.com> 


\section{Giriş}

Hastalıkların ve yaralanmaların insanlığın varoluşu ile görülmeye başladığı ve dolayısıyla tıp mesleğinin de insanlık tarihi kadar eski olduğu söylenebilir. Tıp, tarihin en eski meslek dallarından biri olarak yüzyıllardır birçok farklı coğrafyada ve zamanda uygulanmış ve çeşitli yollarla gelişerek toplumların ihtiyaçlarına cevap vermiştir. Geçmişten gelen tecrübe ve birikimin bir sonraki kuşaklara aktarılması ve yapılan hataların bir daha tekrarlanmaması için tıp mesleğine özgü teknik bilgilerin yanında tarihinin de öğrenilmesi ve özümsenmesi gerekir. Tıp tarihi ile tıbbın hangi temeller üzerine oturduğunun ve hangi gelişim aşamalarından geçtiğinin bilinmesi, geçmiş ile günümüz arasında bir köprü kurularak geriye dönük düşünme alışkanlığının kazandırııması ve bilgilerin doğru bir şekilde aktarımı sağlanmaktadır. ${ }^{1,2}$

Tıp tarihine olan ilginin 19. yy ortalarından başlayarak arttığı görülmektedir. Bu artışın oluşmasına yol açan birden fazla neden sayılabilir. Teorik varsayımlara dayalı hekimlik bilgilerinin pozitif bilimlere dayandırılması; genel tarihe, tarih felsefesine, tarih metoduna ve kültür tarihine dair farklı yaklaşımların ortaya çıkması bu nedenlere örnek gösterilebilir. ${ }^{3}$

Tıp tarihine yönelik artan ilgiye paralel olarak son yıllarda bu alandaki çalışma sayılarında da bir artışın olduğu gözlenmektedir. Ancak günden güne artan çalışmaların belirli bir disiplin içerisinde değerlendirilebilmesi, karşılaştırılabilmesi, yaşanan gelişmelerin takip edilebilmesi ve alana özgü güncel literatür bilgisine ulaşılabilmesi için bilimsel ve istatistiksel olarak yapılan analizlere ihtiyaç duyulmaktadır. Günümüzde bu analizler; atıf indeksi veya dizini, makroskopik inceleme sunan ve genel olarak bilim haritalama yöntemleri adı verilen birçok yazılım ve online hizmet sunucularıyla yapılabilmektedir. ${ }^{4-7}$

Tıp tarihi alanındaki yayınların incelenebilmesi, literatüre en fazla katkı sunan yazar, kurum, üniversite, dergi gibi verilerin tespit edilebilmesi için sağıı ve tıp alanında kullanım popülerliği günden güne artan bibliyometrik analizler kullanılabilir. ${ }^{8-15}$

Farklı birçok disiplinde kullanılan bibliyometrik analizlerin ortaya çıkış sürecine bakıldığında, ilk kez 1922 yılında E. Wyndham Hulme tarafından Cambridge Üniversitesi'nde "istatistiksel bibliyografya" terimi adı altında kullanıldığı görülmektedir. ${ }^{16}$ Daha sonraları Raising'in bu terime 1962 yılında sağlık bilimlerinde alıntılama üzerine yaptığı bir makalesinde yer vermekte, Osareh ise bu yöntemin terim olarak tanımlanmadan önce kullanıldığını ifade etmektedir. ${ }^{17,18}$ Son olarak Alan Pritchard'ın 1969 yılında "istatistiksel bibliyografya mı yoksa bibliyometri mi?" adlı makalesinde istatistiksel bibliyografya terimini yeterince açıklayıcı bulmadığı ve bunun yerine bibliyometriyi kullanmayı önerdiği görülmektedir. ${ }^{16,19}$ Pritchard bibliyometriyi; matematiğin ve istatistiksel yöntemlerin kitaplara ve diğer iletişim ortamlarına uygulanması olarak tanımlamaktadır. ${ }^{8,19}$ Yılmaz'a göre bibliyometri "belli bir alanda, belli bir dönemde ve belli bir ülkede ya da belli bir bölgede kişiler veya kurumlar tarafından üretilmiş yayın paternlerinin ve bu paternler arasındaki ilişkilerin niceliksel olarak analiz edilmesi" dir. ${ }^{16}$

Bibliyometrik analizlerin son yıllarda standart bir değerlendirme yöntemi olarak kullanılmaya başlandığı görülmektedir. Bilimsel çalışmaların değerlendirilmesinde ise en önemli kriteri atıf analizleri oluşturmaktadır. Bibliyometrik analizler ile atıf analizlerinin yanı sıra yazarların, kurumların ve ülkelerin değerlendirilmesi de yapılabilmektedir. ${ }^{20,21}$ Ancak bu ifadeden bibliyometrik analizlerin bir parçası olarak incelenen atıf analizlerinin sonuçlarına bakılarak, az atıf alan ve/veya atıf almayan çalışmaların değersiz ya da az değerli olduğu anlamı çıkarılmamalıdır.

Bibliyometrik analizler bilimsel veri tabanları üzerinden yapılmaktadır. Web of Science (WOS) platformu 21.000'den fazla hakemli dergiye ulaşım sağlamakta, akademik ve bilimsel araştırmalar ile atıf indeksi olarak kullanılmaktadır. Bununla beraber bünyesinde, Science Citation Index Expanded (SCIE), Social Sicence Citation Index (SSCl), Art\&Humanities Citation Index (A\&HCl), Emerging Sources Citation Index (ESCl) olmak 
üzere birçok indekse daha ulaşım sağlamakta ve bibliyometrik analizler için uygun bir alt yapı oluşturmaktadır. ${ }^{22}$

Bu çalışmada 1975-2020 yılları arasında tıp tarihi alanına yönelik yapılan ve WOS veri tabanında yer alan çalışmaların bibliyometrik analizinin oluşturulması, Türkiye'nin bu alana katkı düzeyinin belirlenmesi ve alana özgü en güncel literatür bilgisinin sunulması amaçlanmaktadır.

\section{Gereç ve Yöntem}

Sağlık Bilimleri Üniversitesi / Ankara altyapısıyla erişilen Web of Science (WOS) veri tabanındaki tüm indekslerde (Web of Science Core Collection, $\mathrm{KCl}$ - Korean Journal Database, Russian Science Citiation Index, SciELO Citiation Index) 24-27 Aralık 2020 tarihleri arasında tıp tarihi alanına yönelik bir tarama yapılmıştır. Bu taramada konu (içeriğinde başık, özet, yazar ve anahtar kelimeler vb. gibi seçenekler bulunan) sekmesi hanesine "history of medicine" sözcük gurubu yazılmıştır. Tarama sonucu araştırmaya dâhil edilen ve 19752020 yılları arasında yapılan 5904 çalışmaya ulaşılmıştır. Yaklaşık bir aylık zaman zarfı içerisinde bu çalışmaların yayın yılı, atıf analizi, yayın dili, yayın türü; en fazla çalışma yapan kurum, dergi ve en fazla katkı sağlayan yazar; en fazla katkı sunan ülkeler ve çalışmaların en çok hangi alanlara yoğunlaştığının bibliyometrik analizleri yapılmıştır. Yapılan bu analizler tablo ya da şekil olarak sunulmuş ve elde edilen veriler doğrultusunda yapılan değerlendirmeler alt kısımlarında yazılı olarak ifade edilmiştir. Buna ilaveten Türkiye adresli yayınlar da analiz edilmiş, en fazla katkı sunan üniversiteler ve yazarlar ile en fazla atıf alan yayınlar tespit edilerek birer tabloda gösterilmiştir.

\section{Araştırmanın Kısıtlılığı}

Web of Science veri tabanında bulunan ancak "history of medicine" anahtar kelimesi kullanmayan çalışmalar ile Web of Science veri tabanında taranmayan çalışmalar araştırmanın kısıtlılığı olarak kabul edilmiştir.

\section{Bulgular}

Bulgular kısmında yer alan tablolar ve şekiller WOS veri tabanı verileri kullanılarak oluşturulmuş, şekillerin üst kısmında yer alan toplam atıf sayıları görseli ise WOS veri tabanından alıntılanmıştır. ${ }^{23}$ Tablolarda yer alan "n katlanmıştır" ifadesi, n sayısının toplamının 5904'ten fazla çıktığı anlamına gelmektedir. Bunun nedeni "history of medicine" anahtar kelimesini kullanan ve WOS veri tabanında yer alan bazı çalışmaların, birden fazla branşın tarihini ve araştırma alanını kapsamasından ve farklı yayın türleri ile yayın dillerinde yazılmasından kaynaklanmaktadır. Dolayısıyla yüzdeler ile $n$ sayıları arasında bir uyumsuzluk ortaya çıkmaktadır.

Tıp tarihi alanında 1975-2020 yılları arasında yayımlanan 5904 çalışma beşer yıllık zaman dilimine göre hazırlanmıştır. Bu çalışmaların yıllara göre dağılımı incelendiğinde en fazla çalışmanın yıl olarak 2015'te ( $n=304 ; \% 5,14)$, zaman dilimi olarak da son beş yılda $(n=1364 ; \% 23,10)$ yayımlandığı görülmektedir (Tablo 1). 
Tablo 1. Tıp Tarihine Dair Çalışmaların Yıllara Göre Dağılımı

\begin{tabular}{lc}
\hline Yıllar & Sayı $(\mathbf{n})$ \\
\hline $1975-1980$ & 189 \\
$1981-1985$ & 335 \\
$1986-1990$ & 303 \\
$1991-1995$ & 547 \\
$1996-2000$ & 522 \\
$2001-2005$ & 646 \\
$2006-2010$ & 843 \\
$2011-2015$ & 1155 \\
$2016-2020$ & 1364 \\
Toplam & 5904 \\
\hline
\end{tabular}

Alanlarına göre dağılımı incelenen çalışmalar içerisinde en fazla çalışmanın tarih alanında ( $n=3861 ; \% 65,93)$ yapıldığı görülmektedir (Tablo 2).

Tablo 2. Tıp Tarihine Dair Çalışmaların Araştırma Alanlarına Göre Dağıımı

\begin{tabular}{lc}
\hline Araştırma Alan & Sayı (n) \\
\hline Tarih & 3861 \\
Bilim Tarihi Felsefesi & 1905 \\
Dâhili Tıp & 1661 \\
Sağlık Bakım Hizmetleri & 1277 \\
Nöroloji, Nörobilim & 717 \\
Davranış Bilimleri & 686 \\
Halk, Çevre ve İ̧̧ Sağlığı & 678 \\
Cerrahi & 650 \\
Psikoloji & 597 \\
Deneysel Tıp & 522 \\
Bulaşıcı Hastalıklar & 503 \\
Eğitim Araştırması & 495 \\
Kardiyoloji & 463 \\
Illetişim & 461 \\
Farmakoloji & 449 \\
Patoloji & 375 \\
Psikiyatri & 352 \\
Antropoloji & 338 \\
Kütüphane Bilimi & 336 \\
Solunum Sistemi & 332 \\
\hline *n katlanmıştır.
\end{tabular}

İlk beş yayın türü içerisinde "makale" nin ( $n=5126 ; \% 86,82$ ) ilk sırada yer aldığı görülmektedir (Tablo 3).

Tablo 3. Tıp Tarihine Dair Çalışmaların Doküman Tiplerine Göre Dağılımı

\begin{tabular}{lc}
\hline Yayın Türleri & Sayı $(\mathbf{n})$ \\
\hline Makale & 5126 \\
Biyografi & 1440 \\
Derleme & 1259 \\
Diğer & 742 \\
Editoryal & 650 \\
\hline
\end{tabular}

*n katlanmıştır.

** WOS'da "editorial" şeklinde geçen kelime "Töreci, K. Editoryal Nedir?

ANKEM Derg, 2009;23(4):199-203) künyeli makale referans alınarak

"editoryal" olarak Türkçeleştirilmiştir.

En çok kullanılan ilk on dile ait çalışmalar belirlenmiştir. 30 farklı dilde yapılan 5904 çalışma içerisinde İngilizce yayın sayısının ( $n=4101 ; \% 69,46)$ en yüksek olduğu, bunun yanında bazı çalışmaların birden fazla dilde yazıldığı gözlenmiştir (Tablo 4). 
Tablo 4. Tıp Tarihine Dair Çalışmaların Yayın Dillerine Göre Dağılımı

\begin{tabular}{lc}
\hline Yayın Dili & Sayı (n) \\
\hline İngilizce & 4101 \\
Ispanyolca & 628 \\
Almanca & 392 \\
Rusça & 374 \\
Fransızca & 239 \\
Portekizce & 137 \\
Korece & 58 \\
İtalyanca & 44 \\
Hırvatça & 21 \\
Türkçe & 16 \\
\hline
\end{tabular}

* n katlanmıştır.

Tıp tarihi alanında en çok yayın yapan ilk on kaynak incelendiğinde, en aktif derginin Revista Medica de Chile'nin birinci $(n=184 ; \% 3,11)$, alana özgü yayın yapan Bulletin of the History of Medicine'nin ise ikinci ( $n=129 ; \% 2,18$ ) olduğu görülmektedir (Tablo 5).

Tablo 5. Tıp Tarihine Dair Çalışmaların Yayınlandığı Kaynaklara Göre Dağılımı

\begin{tabular}{lc}
\hline Kaynaklar & Sayı (n) \\
\hline Revista Medica de Chile & 184 \\
Bulletin of the History of Medicine & 129 \\
Social History of Medicine & 92 \\
Wiener Klinische Wochenschrift & 70 \\
Historia Ciencias Saude Manguinhus & 66 \\
Journal of the History Of Medicine and Allies Sciences & 63 \\
American Journal of Industrial Medicine & 61 \\
Medical History & 61 \\
Problemy Sotsial Noi Gigieny & 60 \\
Texas Heart Institute & 58 \\
\hline
\end{tabular}

Atıf sayılarının 1976 yılında bir atıf ile başladığı ve yıllar içerisinde hızlı bir ivme kazanarak 2020 yılı sonu itibari ile toplamda 34237 sayısına (kendine atıf yapmadan, $n=32936$ ) ulaştığı, ayrıca son on yılda gerçekleştirilen atıf sayılarına göre en fazla atfın 2019 yılında ( $n=2867)$ gerçekleştirildiği gözlenmektedir (Şekil 1).

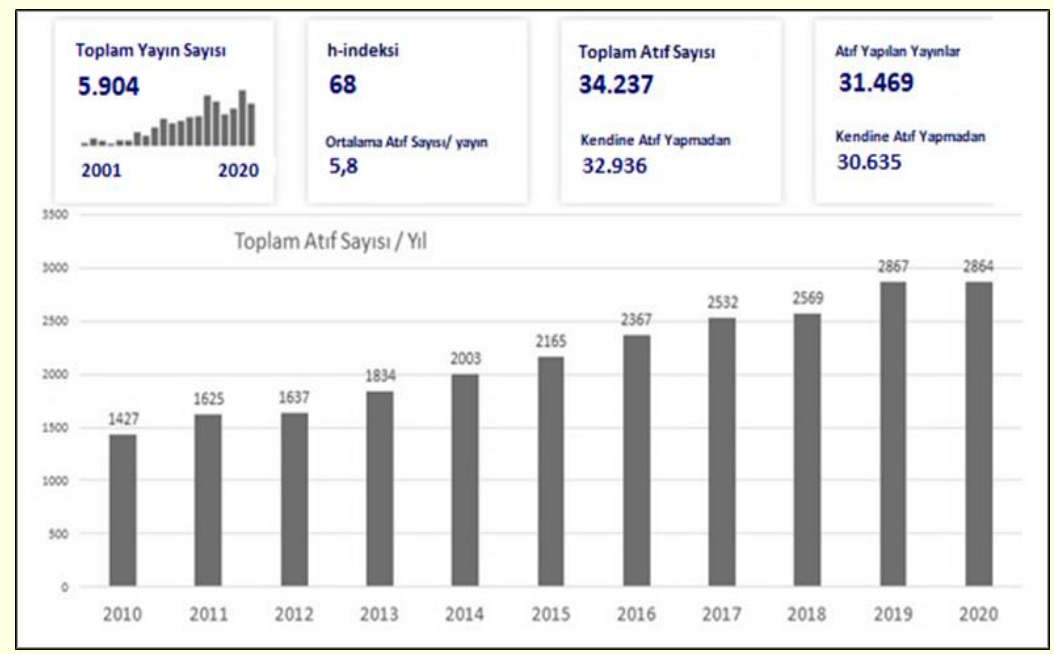

Şekil 1. Tıp Tarihine Dair Çalışmaların Son On Yıldaki Atıf Sayıları

Tıp tarihi ile ilgili yapılan çalışmalara en fazla katkıyı Londra Üniversite'sinin ( $n=131 ; \% 2,21$ ) sunduğu görülmektedir (Tablo 6). En fazla katkı sağlayan 100 kurum incelendiğinde ise Türkiye'den Ankara Üniversitesi'nin $(n=25 ; \% 0,42)$ 45. sırada, Erciyes Üniversitesi'nin de $(n=18 ; \% 0,30)$ 75. sırada yer aldığı gözlenmiştir. 
Tablo 6. Tıp Tarihine Dair Çalışmalara En Fazla Katkı Sağlayan Kurumlar

\begin{tabular}{lc}
\hline Kurumlar & Sayı (n) \\
\hline University of London & 131 \\
Harvard University & 95 \\
Universidad de Chile & 92 \\
University of Calfornia System & 76 \\
University College London & 75 \\
Johns Hopkins University & 56 \\
National Kapodistrian University of Athens & 53 \\
University of Vienna & 46 \\
Assistance Publique Hopitaux Paris APHP & 45 \\
Universita Degli Studi Di Bari Aldo Moro & 43 \\
\hline
\end{tabular}

Literatüre en fazla katkı sağlayan ülkelerin ilk onu sıralanmaktadır. Tıp tarihi ile ilgili yapılan 5904 çalışmada Amerika Birleşik Devletleri'nin ( $n=1499 ; \% 25,39)$ ilk sırada yer aldığı (Tablo 7), Türkiye'nin ise $(n=90 ; \% 1,52)$ bu sıralamada 15. olduğu görülmektedir.

Tablo 7. Tıp Tarihine Dair Yayınların En Fazla Çalışma Yapan Ülkelere Göre Dağılım

\begin{tabular}{lc}
\hline Ülkeler & Sayı (n) \\
\hline Amerika Birleşik Devletleri & 1499 \\
Ingiltere, UK & 610 \\
Almanya & 425 \\
İtalya & 276 \\
Fransa & 245 \\
Şili & 171 \\
Brezilya & 158 \\
Kanada & 155 \\
İspanya & 134 \\
Rusya & 130 \\
\hline
\end{tabular}

Web of Science veri tabanında yer alan Türkiye adresli çalışmaların 2003 yılı (iki adet yayın) itibari ile başladığı ve 2012 yılında hiç bulunmadığı gözlenmiştir. Toplam 90 adet yayından en fazla çalışmanın ise 2019 yılında ( $n=16 ; \% 17,78$ ) yapıldığı görülmektedir (Tablo 8).

Tablo 8. Tıp Tarihine Dair Yayınların En Fazla Çalışma Yapan Ülkelere Göre Dağılım

\begin{tabular}{lc}
\hline Yıllar & Sayı $(\mathbf{n})$ \\
\hline $2003-2012$ & 28 \\
2013 & 4 \\
2014 & 4 \\
2015 & 7 \\
2016 & 7 \\
2017 & 7 \\
2018 & 9 \\
2019 & 16 \\
2020 & 8 \\
Toplam & 90 \\
\hline
\end{tabular}

Türkiye adresli 90 yayına toplamda 317 adet (kendine atıf yapmadan; $n=285$ ) atıf yapılmıştır. Son on yılın atıf sayıları incelendiğinde, en fazla atıfın 2019 yııında gerçekleştirildiği (n=46) görülmektedir (Şekil 2).

Web of Science veri tabanında bulunan Türkiye adresli 90 yayından atıf sıralamasına göre ilk onu bulunmaktadır. Yayın yılları ile yayınlandıkları yıldan itibaren aldıkları atıf sayıları da yine aynı tabloda yer almaktadır. İlgili tabloya göre en fazla atıf alan yayının Gazi Üniversitesi'nden çıktığı görülmektedir (Tablo 9). Türkiye adresli yayınlar incelendiğinde ise en fazla katkı sunan kurumların sırası ile Ankara Üniversitesi, Erciyes Üniversitesi ve İstanbul Üniversitesi olduğu tespit edilmiştir. 


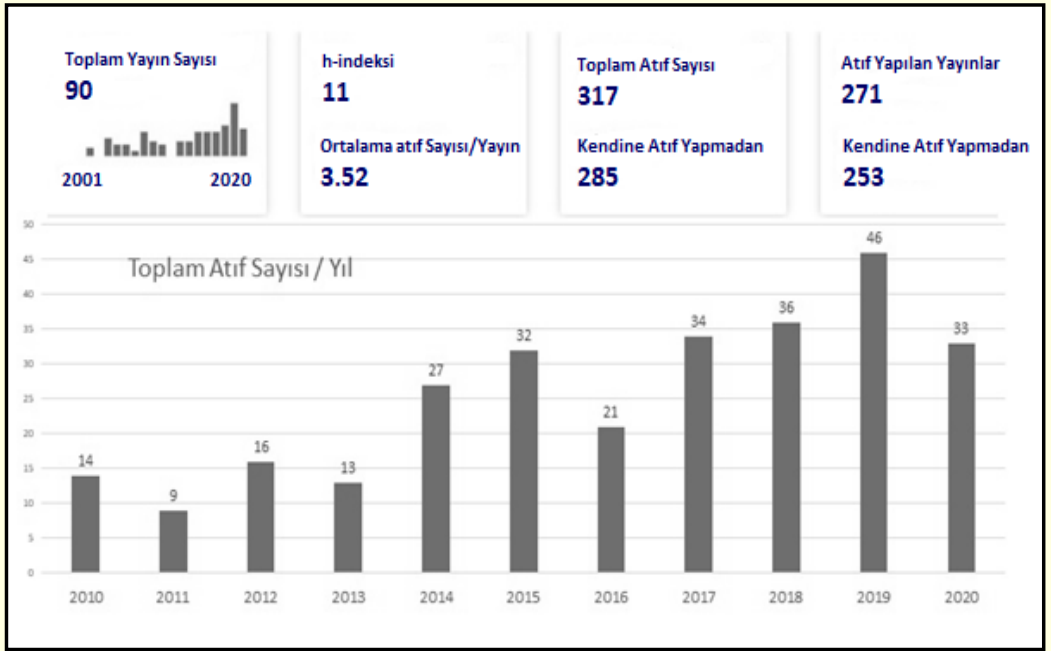

Şekil 2. Türkiye Adresli 90 Adet Yayının Atıf Değerlendirmesi

Tablo 9. Türkiye Adresli Yayınlardan En Fazla Atıf Alanlar ve Araștırma Alanları

\begin{tabular}{|c|c|c|c|c|c|c|}
\hline Dergi Adı & Yayın Adı & Yazar & $\begin{array}{l}\text { Yayın } \\
\text { Yılı }\end{array}$ & Atıf & Üniversite & $\begin{array}{l}\text { Araştırma } \\
\text { Alanları }\end{array}$ \\
\hline $\begin{array}{l}\text { Journal of } \\
\text { Urology }\end{array}$ & $\begin{array}{l}\text { Consumption of } \\
\text { historical and current } \\
\text { phytotherapeutic } \\
\text { agents for urolithiasis: } \\
\text { A critical review. }\end{array}$ & $\begin{array}{l}\text { Gurocak, S; } \\
\text { Kupeli, B. }\end{array}$ & 2006 & 38 & Gazi Üniv & $\begin{array}{l}\text { Üroloji, } \\
\text { Nefroloji }\end{array}$ \\
\hline Surgical Neurology & $\begin{array}{l}\text { The earliest document } \\
\text { regarding the history of } \\
\text { cranioplasty from the } \\
\text { Ottoman era. }\end{array}$ & $\begin{array}{l}\text { Aciduman, A; } \\
\text { Belen, D. }\end{array}$ & 2007 & 26 & $\begin{array}{l}\text { Ankara Etlik } \\
\text { Intisas EAH }\end{array}$ & $\begin{array}{l}\text { Nörobilim, } \\
\text { Nöroloji, } \\
\text { Cerrahi }\end{array}$ \\
\hline $\begin{array}{l}\text { Journal of } \\
\text { Integrative } \\
\text { Medicine }\end{array}$ & $\begin{array}{l}\text { The use of Chinese } \\
\text { herbal drugs in } \\
\text { Islamic medicine }\end{array}$ & $\begin{array}{l}\text { Heyadri, M; } \\
\text { Hashempur, } \mathrm{MH} \text {; } \\
\text { Ayati, } \mathrm{MH} \text {; et al. }\end{array}$ & 2015 & 25 & $\begin{array}{l}\text { Shiraz Univ, } \\
\text { Fasa Univ, } \\
\text { Tehran Univ, } \\
\text { Fatih Sultan } \\
\text { Mehmet Vakıf } \\
\text { Üniv }\end{array}$ & $\begin{array}{l}\text { Tamamlayıcı } \\
\text { Tıp }\end{array}$ \\
\hline Neurosurgery & $\begin{array}{l}\text { Herophilus of } \\
\text { chalcedon: A } \\
\text { pioneer } \\
\text { neuroscience }\end{array}$ & $\begin{array}{l}\text { Acar, F; } \\
\text { Naderi, S; } \\
\text { Guvencer, } \\
\text { M; Ture, U. }\end{array}$ & 2005 & 22 & $\begin{array}{l}\text { GATA, } \\
\text { Dokuz Eylül Üniv, } \\
\text { On Dokuz Mayıs } \\
\text { Üniv }\end{array}$ & $\begin{array}{l}\text { Nörobilim, } \\
\text { Nöroloji, } \\
\text { Cerrahi }\end{array}$ \\
\hline $\begin{array}{l}\text { Pharmaceutical } \\
\text { Biology }\end{array}$ & $\begin{array}{l}\text { The poetential } \\
\text { medicinal value of } \\
\text { plants from } \\
\text { Asteraceae family } \\
\text { with antioxidant } \\
\text { defense enzymes as } \\
\text { biological targets }\end{array}$ & $\begin{array}{l}\text { Koc, S; Isgor } \\
\text { BS; Isgor, YG; } \\
\text { et al. }\end{array}$ & 2015 & 14 & $\begin{array}{l}\text { Ankara Üniv, } \\
\text { Atilim Üniv }\end{array}$ & $\begin{array}{l}\text { Bitki Bilimleri, } \\
\text { Tıbbi } \\
\text { Laboratuvar } \\
\text { Teknolojisi, } \\
\text { Farmakoloji, } \\
\text { Eczacılık }\end{array}$ \\
\hline $\begin{array}{l}\text { Neurosorgical } \\
\text { Review }\end{array}$ & $\begin{array}{l}\text { What does Al- } \\
\text { Qanun Fi Al-Tibb } \\
\text { (The Canon of } \\
\text { Medicine) say on } \\
\text { head injuries? }\end{array}$ & $\begin{array}{l}\text { Aciduman, A; } \\
\text { Arda, B; } \\
\text { Ozakturk, FG; } \\
\text { Telatar UF. }\end{array}$ & 2009 & 13 & Ankara Üniv & $\begin{array}{l}\text { Nörobilim, } \\
\text { Nöroloji, } \\
\text { Cerrahi }\end{array}$ \\
\hline Urology & $\begin{array}{l}\text { Urologic techniques } \\
\text { of Serefeddin } \\
\text { Sabuncuoglu in the } \\
\text { 15th century } \\
\text { Ottoman period }\end{array}$ & $\begin{array}{l}\text { Verit, A; } \\
\text { Aksoy, S; } \\
\text { Kafali, H; } \\
\text { Verit, FF. }\end{array}$ & 2003 & 13 & Harran Üniv & $\begin{array}{l}\text { Üroloji, } \\
\text { Nefroloji }\end{array}$ \\
\hline
\end{tabular}




\begin{tabular}{|c|c|c|c|c|c|c|}
\hline Neurosurgery & $\begin{array}{l}\text { The Royal Book by } \\
\text { Haly Abbas from the } \\
\text { 10th century: One } \\
\text { of the earliest } \\
\text { illustrations of the } \\
\text { surgical approach to } \\
\text { skull fractures }\end{array}$ & $\begin{array}{l}\text { Aciduman, A; } \\
\text { Arda, B; } \\
\text { Kahya, E; } \\
\text { Belen D. }\end{array}$ & 2010 & 11 & $\begin{array}{l}\text { Ankara Üniv, } \\
\text { Ankara Numune } \\
\text { EAH }\end{array}$ & $\begin{array}{l}\text { Nörobilim, } \\
\text { Nöroloji, } \\
\text { Cerrahi }\end{array}$ \\
\hline Surgical Neurology & $\begin{array}{l}\text { History Of } \\
\text { peripheral nerve } \\
\text { repair: may the } \\
\text { procedure have } \\
\text { been practiced in } \\
\text { Hippocratic School? }\end{array}$ & $\begin{array}{l}\text { Belen, D; } \\
\text { Aciduman, A; } \\
\text { Er, Uygur }\end{array}$ & 2009 & 11 & $\begin{array}{l}\text { Ankara Etlik Ihtisas } \\
\text { EAH }\end{array}$ & $\begin{array}{l}\text { Nörobilim, } \\
\text { Nöroloji, } \\
\text { Cerrahi }\end{array}$ \\
\hline Neurosurgery & $\begin{array}{l}\text { Peripheral nerve } \\
\text { disorders and } \\
\text { treatment } \\
\text { strategies according } \\
\text { to avicenna in his } \\
\text { medical treatise, } \\
\text { Canon of medicine. }\end{array}$ & $\begin{array}{l}\text { Aciduman, A; } \\
\text { Er, U; Belen } \\
\text { D. }\end{array}$ & 2009 & 11 & $\begin{array}{l}\text { Ankara Univ, } \\
\text { Ankara Numune } \\
\text { EAH, } \\
\text { Yildirim Beyazıt } \\
\text { Dışkapı EAH }\end{array}$ & $\begin{array}{l}\text { Nörobilim, } \\
\text { Nöroloji, } \\
\text { Cerrahi }\end{array}$ \\
\hline
\end{tabular}

Bir yayın birden fazla alanın içinde sayılabilmektedir. Türkiye adresli yayınların ilk on araştırma alanına göre dağılımı incelendiğinde, tarih $(n=53 ; \% 58,88)$ alanında yapılan yayınların ilk sırada yer aldığı görülmektedir (Tablo 10).

Tablo 10. Türkiye Adresli Yayınların Araştırma Alanlarına Göre Dağılımı

\begin{tabular}{lc}
\hline Yayın Türleri & Sayı (n) \\
\hline Tarih & 53 \\
Cerrahi & 31 \\
Dâhili Tıp & 28 \\
Nörobilim / Nöroloji & 27 \\
Illetişim & 15 \\
Sanat & 13 \\
Davranış Bilimleri & 12 \\
Anatomi & 10 \\
Pediatri & 9 \\
Antropoloji & 8 \\
\hline *n katlanmıştır. &
\end{tabular}

\section{Tartışma}

Bibliyometrik analizler ile yazarlar, kurumlar, dergiler, makaleler başta olmak üzere farklı birçok yayının bilimsel yönden değerlendirilmesi yapılabilmektedir. Bu analizler ile yayının kendi içerisinde ve diğer yayınlar ile olan etkileşimleri de görülebilmektedir. Tabi ki bilimsel değerlemenin en önemli göstergelerden biri de atıf analizidir. Bibliyometrik analizler ile atıf göstergelerine ve bilimsel olarak kullanılabilecek disiplinler arası karşılaştırılmalı sonuçlara da ulaşılabilmektedir. ${ }^{7,18,20,21}$

Adını sıkça duymaya başladığımız bibliyometrik analiz çalışmalarının henüz çok fazla olmamakla birlikte sağlık alanındaki uygulamalarıyla da karşılaşılmaktadır. Kürklü’nün biyoetik ile ilgili çalışmaların değerlendirilmesi, Hekimoğlu ve ark. tarafından hazırlanan Türkiye'de HIV pozitif bireylere karşı yapılan epidemiyolojik çalışmaların değerlendirmesi, Tran ve ark. tarafından çalışılan HIV/AIDS hastalığının ekonomik olarak değerlendirilmesi, Bozdemir'in hastalık maliyetleri analizleri, Ercan ve Azkan tarafından yapılan bir tıp dergisinin analizi, Brandt ve ark.'nın doğum ve kadın hastalıkları ile ilgili çalışmaları ve son olarak Fan ve ark. Covid-19 ile ilgili çalışmaları gibi bibliyometrik analizler sağlık alanındaki güncel örneklerden birkaçıdır. ${ }^{8,}$ 10-15 
Son yıllarda tıp tarihi ile ilgili çalışmaların da arttığı açıkça görülmektedir. Bu araştırma kapsamında taranan yayınlarda tıp tarihi literatürüne ait yayınlara özgü bibliyometrik analize rastlanmamıştır. Bu açıdan bakıldığında bu çalışmanın tıp tarihi alanında yapılmış yayınları bir bütün olarak inceleyen ilk çalışmalardan biri olacağı ve literatüre katkı sağlayacağı düşünülmektedir.

Tıp tarihine dair çalışmaların yıllara göre dağılım tablosu incelendiğinde, son yıllardaki çalışma sayılarının attığı ve tüm çalışmaların \%23,10'unun son beş yılda yapıldığı görülmektedir (Tablo 1). Bu durumun tıp tarihi çalışmaları için ümit verici ve geçmişe bakılarak geleceğimize yön verebilme adına da önemli olduğu değerlendirilebilir. Tıp tarihine dair çalışmaların araştırma alanlarına göre dağılımı genel olarak incelendiğinde, çalışmaların $\% 65,93^{\prime}$ lük bölümünün ve Türkiye özelinde $\% 58,88^{\prime}$ lik bölümünün tarih araştırma alanı ile ilişkilendirilmesi bu tezi destekler niteliktedir (Tablo 2 ve 10).

Günümüzde akademisyenler, yaptıkları akademik çalışmalarla ürettikleri bilgileri farklı şekillerde yayınlayarak toplumsal sorumluluklarını yerine getirmektedirler. ${ }^{24}$ Çalışma kapsamında elde ettiğimiz veriler incelendiğinde tıp tarihi alanında çalışmaların yayın tiplerine yönelik yapılan analizlerinde ise en fazla “makale"nin ( $n=5126)$ yer aldığı görülmektedir (Tablo 3). Yapılan çalışmaların daha etkili olabilmesi için yazıya dökülerek sunulmasının, akademisyenlerin ve çalışmalarının değerlendirebilme araçlarından biri olması makale sayısındaki çokluğun nedenleri arasında değerlendirilebilir. En fazla çalışmanın İngilizce dilinde $(n=4101)$ yapılmış olması (Tablo 4), yayımlanan dergilerin büyük bir çoğunluğunun İngilizce olmasından ve daha çok araştırmacıya ulaşabilme gayesinden dolayı kaynaklandığı düşünülmektedir.

Akademik yaşamda dergilerin önemi, bir iletişim aracı olmanın ve kalıcı bir kayıt sağlamanın ötesindedir. Dergilerde yayınlanan akademik makaleler, yapılan araştırmaların nihai çıktılarıdır. Bu çıktılar, araştırmacıların performansı ve üretkenliğini, yayınların sayısı ve yayınlandıkları dergilere göre değerlendirmeye yardımcı olmaktadır. Bu nedenle dergiler, akademik dünyanın vazgeçilmez bir parçası haline gelmişlerdir. ${ }^{25}$ Çalışmamız kapsamında tıp tarihi alanında en fazla çalışmanın (Latin Amerika, Portekiz, İspanya ve Güney Afrika'nın önde gelen dergilerini indeksleyen) SciELO Citation Index veri tabanı ile dâhiliye, alt uzmanlık alanları, klinik tıp ve biyomedikal araştırmalar konusunda yayım yapan Revista Medica de Chile $(\mathrm{n}=182)$ dergisinde yayınlandığı görülmektedir. En fazla yayın sıralamasında ikinci sırada yer alan derginin ise tıp tarihi alanına özgü yayım yapan Bulletin of the History of Medicine $(n=129)$ dergisi olduğu gözlenmektedir (Tablo 5). Kapsam ve içerik açısından bu iki derginin başı çekmesinin hayli doğal olduğu düşünülmektedir.

Tıp tarihine dair çalışmalara en fazla katkı sağlayan kurumlar incelendiğinde, ilk üç sırada Londra Üniversitesi/ İngiltere, Harvard Üniversitesi/ ABD ve Şili Üniversitesi/ Şili'nin yer aldığı görülmektedir (Tablo 6). Bu sonucun ortaya çıkmasında, üniversitelerin bilim politikasının ya da araştırmacıların tıp tarihine yönelik araştırma motivasyonlarının etkisi olabileceği değerlendirilmektedir.

Dergiler ve yazarlar atıf temelli değerlendirilmektedir. İstatistik temelli bir derginin editörü olan ve bibliyometrik analizler üzerine yayınları bulunan Glanzel, dergilerinin bilimsel atıflarının tek bir ölçüt üzerinden değerlendirilmesini tartışmakta ve gelişen standartlar doğrultusunda bibliyometrik analizler ile daha güvenilir ve geçerli analiz sonuçlarının ortaya çıkabileceğini ifade etmektedir. ${ }^{26,27}$

Tıp tarihi alanında 1975-2020 yılları arasında yapılmış 5904 yayının atıf sayıları incelendiğinde, 1976 yılında bir atıf ile başladığı, yıllar içerisinde hızlı bir artış yaşadığı ve bu süreç içerisinde makalede değerlendirmeye alınan tüm yayınlara toplam 34237 atıf yapıldığı görülmektedir (Şekil 1). Bu her bir yayın için ortalama 5,8 atfın yapııdığı anlamına gelmektedir. Atıf sayılarının yıllara göre artışı, artan yayın sayısına paralel olarak alana özgü daha fazla tartışmanın ve araştırmanın yapıldı̆ının göstergesi olarak kabul edilebilir. Ayrıca bu teknolojik imkânların kullanımının bire bir yansıması olarak da değerlendirilebilir. Nitekim Smith atıf analizi 
çalışmasında, atıf analizi konusunda geliştirilen yeni teknikliklerle ve bilgisayarın kullanımı ile daha çok dizine ulaşılarak atıfların arttığını belirtmektedir. ${ }^{7}$

Literatüre en fazla katkı sunan ülkeler sıralamasında Amerika Birleşik Devletlerinin ( $n=1499)$ birinci sırada olduğu görülmektedir (Tablo 7). Türkiye ise 90 makale ile katkı sağlamıştır (Tablo 8). Türkiye adresli olarak yapılan bu çalışmaların 2003 yılında iki adet yayın ile başladığı, en fazla çalışmanın 2019 ( $n=16)$ yılında çıkarıldığı, toplamda 317 atıf alındığı ve yayın başına 3,52 atfın yapıldığı görülmektedir (Şekil 2). Bu bulgu, Türkiye'deki akademisyenlerin tıp tarihi literatürüne olan katkılarının son beş yılda dikkate değer bir şekilde arttığını bizlere göstermektedir.

Türkiye adresli en fazla atıf alan çalışmaların sıralandığı (Tablo 9)'da, Ürolitiyazisin tedavisine dair eleştirel bir derleme olan çalışmanın 38 atıf ile birinci, Osmanlı dönemine ait kraniyoplastiye dair belgeye ait çalışmanın 26 atıf ile ikinci ve Çin'de kullanılan bitkisel ilaçların İslam tıbbında kullanılmasına dair çalışmanın ise 25 atıf ile üçüncü sırada yer aldığı görülmektedir. Buna karşın "yıllık ortalama atıf sayısı"na göre sıralama yapıldığında 3,57 ortalama ile atıf sıralamasında üçüncü olan çalışmanın tabloda ilk sırada yer alabildiği gözlenmiştir. Yani yayınlar sadece atıf sayısına göre değil aynı zamanda yıllık ortalama alınan atıf sayısı üzerinden de değerlendirilebilmektedir. ${ }^{28-30}$

Türkiye adresli yayınlarda en fazla katkı sunan kurumlar sıralamasında Ankara Üniversitesi'nin ilk sırada yer aldığı, devamında Erciyes ve İstanbul Üniversitesi'nin geldiği; araştırma alanlarına göre ise en fazla çalışmanın tarih, cerrahi ve dâhiliye alanında yapıldığı görülmektedir (Tablo 9-10).

Web'in büyük etkisi ve birçok farklı programın kullanımı ile daha fazla atıf analizlerinin yapılmaya başladığı görülmüştür. ${ }^{31}$ Bu çalışma ile tıp tarihine özgü atıf analizlerini de içeren bibliyometrik bir analiz yapılmıştır. Yapılan analizler zamana özgü istatistiki bilgiler içermekte ve nicel bir değerlendirme sunmaktadır. Bu nedenle sadece nicel açıdan bakılabilen ve nitel bir değerlendirmeye tabi tutulamayan ve WOS veri tabanında kayıtlı indekslerde yer almayan tıp tarihi ile ilgili yayınlar da bu çalışmanın kısıtılıkları arasında değerlendirilebilir.

\section{Sonuç}

Sonuç olarak, tıp tarihi alanına yönelik yapılan bu bibliyometrik analiz çalışması ile literatüre katkı sunmak, bu alanda çalışma yapmayı planlayan araştırmacılara farkındalık kazandırmak ve rehberlik etmek istenmiştir.

\section{Bilgi}

Makalenin hazırlanmasında herhangi bir kişi ya da kuruluştan destek alınmamıştır. Yazarlar arasında çıkar çatışması bulunmamaktadır.

Web of Science veri tabanından elde ettiğimiz verileri teknik açıdan analiz etme sürecinde bizlere destek olan Sağlık Bilimleri Üniversitesi, Gülhane Tıp Fakültesi, Tıp Tarihi ve Deontoloji Anabilim Dalı doktora öğrencisi, Sercan KÜRKLÜ’ye teşekkür ederiz.

\section{Araştırmacı Katkı Oranı Beyanı}

Özgür Kuş: Fikir/kavram, tasarım, denetleme/danışmanlık, veri toplama veya işleme, analiz veya yorum, kaynak taraması, makalenin yazımı, eleştirel inceleme.

Arif Hüdai Köken: Denetleme/danışmanlık, veri toplama veya işleme, analiz veya yorum, kaynak taraması, makalenin yazımı, eleştirel inceleme. 


\section{Kaynaklar}

1. Bârsu C. History of medicine between tradition and modernity. Clujul Med 2017; 90(2): 243-245. DOI:10.15386/cjmed-794

2. Bayat AH. Tıp Tarihi. İstanbul: Merkezefendi Geleneksel Tıp Derneği; 2016. http://www.zeytinburnu.istanbul/Document/FileManager/tip-tarih-kitabi.pdf

3. Kazancıgil A. Türkiye'de Tıp Tarihi. Türkiye Araştırmaları Lit Derg 2004; 2(4): 213-232.

4. Bornmann L, Marx W. HistCite analysis of papers constituting the $\mathrm{h}$ index research front. J Informetr 2012; 6(2): $285-288$. DOI:10.1016/j.joi.2011.11.001

5. Jan van Eck N, Waltman L. Software survey: VOSviewer, a computer program for bibliometric mapping. Sci 2010; 84: 523-538. DOI:10.1007/s11192-009-0146-3

6. Stasko J, Görg C, Liu Z. Jigsaw: Supporting investigative analysis through interactive visualization. Inf Vis 2008; 7(2): 118-132. DOI:10.1057/palgrave.ivs.9500180

7. Smith LC. Citation analysis. Libr Trends 1981; 30(1): 83-106.

8. Kürklü S. Biyoetik Konusunda Yapılan Araştırmaların Bibliyometrik Analizi. Türkiye Biyoetik Derg 2019; 6(3): 87-99.

9. O'Connor E, Nason G, O'Brien MF. Ireland's contribution to ürology and nephrology research in the New Millennium: a Bibliometric analysis. Ir J Med Sci 2017; 186(2): 371-377. DOI:10.1007/s11845-016-1485-8.

10. Hekimoğlu CH, Lüleci D, Bilgin AC. Türkiye'de HIV Pozitif Bireylerde Yapılmış Epidemiyolojik Çalışmaların Bibliyometrik Incelemesi. Türkiye Halk Sağlığı Derg 2017; 15(1):1-25. DOI:10.20518/tjph.326771

11. Tran BX, et al. Economic evaluation studies in the Field of HIV/AIDS: Bibliometric analysis on research development and scopes. BMC Health Serv Res 2019; 19(1): 1-12. DOI:10.1186/s12913-019-4613-0

12. Bozdemir E, Taşlı M. Hastalık Maliyet Analizinin Bibliyometrik ve Doküman Açısından İncelemesi. Konuralp Tıp Derg. 2018; 10(3): 408-419. DOI:10.18521/ktd.449264

13. Ercan S ve ark. Süleyman Demirel Üniversitesi Tıp Fakültesi Dergisi'nin Son 10 Yılının Bibliyometrik Analizi. SDÜ Tıp Fakültesi Derg 2019; 26(2): 123-129. DOI:10.17343/sdutfd.560909

14. Brandt JS, et al. A Bibliometric analysis of top-cited journal articles in obstetrics and gynecology. JAMA Netw Open 2019; 2(12): 1-11. DOI:10.1001/jamanetworkopen.2019.18007

15. Fan J, et al. Bibliometric analysis on COVID-19: A comparison of research between English and Chinese studies. Front Public Heal. 2020;8(August):1-10. doi:10.3389/fpubh.2020.00477

16. Yılmaz M. Türkiye'de Kütüphane ve Enformasyon Bilimi Alanında Bilimsel İletişimin Meslek Dergilerinde Yansıması: Bibliyometrik Bir Analiz. In: Yontar A, ed. Türkiye'de Kütüphane ve Enformasyon Biliminin Kurumsal Gelişimi. İstanbul; 2001: 29-48.

17. Raisig LM. Statistical bibliography in the health sciences. Bull Med Libr Assoc 1962;50(2):450-461.

18. Osareh F. Bibliometrics, citation analysis and co-citation analysis: A review of literature I. Libri 1996; 46(3): 149-158. DOI:10.1515/libr.1996.46.3.149

19. Pitchard A. Statistical bibliography or bibliometrics. J Doc 1969; 25(4): 348-349.

20. Glänzel W. Bibliometrics as a research field, a course on theory and application of bibliometric indicators. Course Handouts; 2003.

https://www.researchgate.net/publication/242406991_Bibliometrics_as_a_research_field_A_course_on_theory_and_applica tion_of_bibliometric_indicators

21. Koehler W. Information science as "little science" :The Implications of a bibliometric analysis of the journal of the American Society for information science. Scientometrics 2001; 51: 117-132.

22. ULAKBIM. Web of Science Core Collection. ULAKBiM. Published 2019. https://cabim.ulakbim.gov.tr/wpcontent/uploads/sites/4/2019/11/WS388947497_Turkey-Brochure_V3_RGB_TR.pdf

23. WOS. Web of

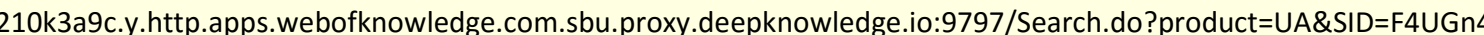
DeebsIH2bZD9W\&search_mode=GeneralSearch\&prID=69b3b8c8-4764-4f8f-864f-708fbe39147a.

24. Kaur CD. Research publications : Need for academicians. Asian J Res Pharm Sci 2013; 3(4): 220-228.

25. Rallison SP. What are journals for? Ann R Coll Surg Engl 2015;97(2):89-91. DOI:10.1308/003588414X14055925061397

26. Glänzel W, Moed H. Journal impact measures in bibliometric research. Scientometrics 2002; 53(2): 171-193. DOI:10.1023/A:1014848323806

27. Glänzel W. The need for standards in bibliometric research and technology. Scientometrics 1996; 35: 167-176. https://link.springer.com/article/10.1007/BF02018475

28. Gürocak S, Küpeli B. Consumption of historical and current phytotherapeutic agents for urolithiasis: A critical review. J Urol 2006; 176(2): 450-455. DOI:10.1016/j.juro.2006.03.034

29. Acıduman A, Belen D. The earliest document regarding the history of cranioplasty from the Ottoman era. Surg Neurol 2007; 68(3): 349-352. DOI:10.1016/j.surneu.2006.10.073

30. Heyadri M, et al. The use of chinese herbal drugs in Islamic medicine. J Integr Med 2015; 13(6): 363-367. DOI:10.1016/S20954964(15)60205-9

31. Meho LI. The rise and rise of citation analysis. Phys World 2007; 20(1): 32-36. DOI:10.1088/2058-7058/20/1/33 